\title{
Investigation of myoepithelial cell differentiation into Schwann-like cells in salivary adenoid cystic carcinoma associated with perineural invasion
}

\author{
WEI CHEN ${ }^{1,2}$, SHAOZHONG DONG ${ }^{3}$, JUN ZHOU $^{3}$ and MOYI SUN ${ }^{1}$ \\ ${ }^{1}$ Department of Oral and Maxillofacial Surgery, School of Stomatology, Fourth Military Medical University, Xi'an, Shannxi; \\ ${ }^{2}$ Department of Stomatology, Nanjing Jinling Hospital, Nanjing University School of Medicine, Nanjing, Jiangsu; \\ ${ }^{3}$ Department of Oral Pathology, School of Stomatology, Fourth Military Medical University, Xi'an, Shannxi, P.R. China
}

Received February 26, 2012; Accepted July 4, 2012

DOI: $10.3892 / \mathrm{mmr} .2012 .1003$

\begin{abstract}
Perineural invasion (PNI) is common in salivary adenoid cystic carcinoma (SACC). The aim of the present study was to explore the association of the Schwann-like cell differentiation with PNI in SACC. Twenty-eight cases of SACC and 10 cases of acinic cell carcinoma (ACA) were examined for the expression of the Schwann cell markers Leu-7 by immunohistochemical staining. The correlation between Leu-7 expression and PNI was analyzed using $\kappa$ analysis. Immunofluorescence double-staining and preembedding immunogold-silver cytochemistry were used to detect the co-expression and the location of Leu-7 and the myoepithelial cell marker $\alpha$-smooth muscle actin ( $\alpha$-SMA). PNI was identified in 16 SACCs $(57.1 \%)$ and 1 ACA (10\%) and the overexpression of Leu-7 was detected in 22 SACCs $(78.6 \%)$ and in none of the ACAs $(0 \%)$. The differences between PNI and Leu-7 expression in SACC and ACA were significant $(\mathrm{P}<0.05)$. A correlation was identified between the expression of Leu-7 and PNI in SACC ( $\kappa=0.533, \mathrm{P}=0.01)$. In SACC, Leu-7 and $\alpha$-SMA were co-expressed in the cytoplasm in the same myoepithelial cells. We suggest that Schwann-like cell differentiation correlates with PNI in SACC and that the differentiation of myoepithelial into Schwann-like cells may be one of the mechanisms through which PNI occurs in SACC.
\end{abstract}

\section{Introduction}

Salivary adenoid cystic carcinoma (SACC) is one of the most frequent malignant salivary gland tumors, constituting approximately $8 \%$ of all salivary gland neoplasms (1). SACC is

Correspondence to: Dr Moyi Sun, Department of Oral and Maxillofacial Surgery, School of Stomatology, Fourth Military Medical University, Chang Le Xi Road 145, Xi'an, Shannxi 710032, P.R. China

E-mail: moyisun@yahoo.cn

Key words: adenoid cystic carcinoma, perineural invasion, Schwann-like cell differentiation, myoepithelial cell, Leu-7 known for its prolonged clinical course and delayed onset of distant metastases (2). Perineural invasion (PNI), a frequent occurrence in SACC, is difficult to identify clinically, which may prevent a complete surgical resection (3). Vrielinck et al reported a correlation between PNI and poor prognosis (4).

Spindle cell melanoma is a melanoma that has a notable propensity for PNI. Iwamoto et al $(5,6)$ demonstrated that Schwann cell markers, including the p75 neurotrophin receptor (p75NTR) and glial fibrillary acidic protein (GFAP), were overexpressed in spindled melanoma compared with the epithelioid melanoma which does not have the characteristics of PNI. In addition, the authors hypothesized that Schwann cell differentiation may be involved in the process of PNI. Leu-7 (human natural killer-1, HNK-1) belongs to the CD57 antibody group. Leu-7 may react with antigens in the medullary sheath of the central and peripheral nervous systems and is regarded as a new Schwann cell marker (7). $\alpha$-smooth muscle actin ( $\alpha$-SMA) is regarded as a useful probe in the study of smooth muscle differentiation in normal and pathological conditions (8). The expression of $\alpha$-SMA has been observed in human myoepithelial cells of salivary (9), mammary (10), sweat (11) and bronchial mucous glands (12).

The aim of the current study was to investigate the expression pattern of a new Schwann cell marker (Leu-7) and $\alpha$-SMA in SACC and acinic cell carcinoma (ACA) and to confirm the correlation between Schwann-like cell differentiation and PNI in SACC.

\section{Patients and methods}

Patients and samples. The present study comprised 28 SACC patients (16 males and 12 females; mean age, 50 years; range, 26-67) and 10 ACA patients (6 males and 4 females; mean age, 51.4 years; range, 31-65) treated at the Department of Oral and Maxillofacial Surgery, School of Stomatology, Fourth Military Medical University between 2004 and 2008. The present study was approved by the Ethics Committee of the Fourth Military Medical University. Informed consent was obtained from all subjects prior to obtaining the tissue samples during surgery.

Samples were divided into two sections. For immunohistochemical staining and hematoxylin and eosin (H\&E) staining, 
one section was fixed immediately in $10 \%$ formalin for $24 \mathrm{~h}$ and was embedded in paraffin. Subsequently, $4-\mu \mathrm{m}$ serial sections were prepared with a microtome. For pre-embedding immunogold-silver cytochemistry, the tissue was incised into a $2 \times 2 \mathrm{~mm}$ slice and fixed into a mixture of $4 \%$ paraformaldehyde, $0.05 \%$ glutaraldehyde and $15 \%$ saturated picric acid in $0.1 \mathrm{M}$ phosphate buffer $(\mathrm{pH} 7.4)$ at room temperature.

Assessment of PNI. Slides were prepared from each sample using 4- $\mu \mathrm{m} \mathrm{H \& E}$-stained serial sections and reviewed by two independent oral pathologists who were blind to the clinical findings. The presence or absence of microscopic PNI was recorded.

Immunohistochemical staining. Mouse anti-human Leu-7 was used as the primary antibody and biotinylated goat antimouse IgG was used as the secondary antibody. The two antibodies were reacted with a streptavidin-biotin-peroxidase complex. Briefly, sections were mounted on glass slides and air-dried. Dewaxing and quenching of endogenous peroxidase was carried out using $3 \% \mathrm{H}_{2} \mathrm{O}_{2} /$ methanol and subsequently protease digestion was carried out for antigen retrieval. The samples were then incubated in goat serum (Invitrogen, Carlsbad, CA, USA) at 1:10 dilution for $20 \mathrm{~min}$ to block non-specific binding. Mouse anti-human monoclonal antibody Leu-7 (Abcam, Cambridge, MA, USA) was diluted in phosphate-buffered saline (PBS)/0.3\% bovine serum albumin (Sigma-Aldrich, St. Louis, MO, USA) and used at a predetermined optimal dilution of 1:25. Following overnight incubation at $4^{\circ} \mathrm{C}$, the sections were incubated for $30 \mathrm{~min}$ at $37^{\circ} \mathrm{C}$ in goat anti-mouse $\mathrm{IgG}$ (Invitrogen). The peroxidase-labeled streptavidin (Invitrogen) was then added for $30 \mathrm{~min}$ at $37^{\circ} \mathrm{C}$. The substrate color reaction was developed by incubation in liquid diaminobenzamine (DAB; Dako, Glostrup, Denmark). For the negative control sections, the primary antibody was replaced by non-immune normal goat serum. The results of immunohistochemical staining were evaluated by two independent pathologists blind to the clinical findings.

Immunofluorescence double-staining and confocal laser scanning microscopy (CLSM) study. A total of 22 samples that expressed Leu-7 were included in immunofluorescence doublestaining carried out. Briefly, sections were stored and then exposed to antigen retrieval. Mouse anti-human monoclonal antibody Leu-7 (Abcam, 1:50) and rabbit anti-human polyclonal antibody $\alpha$-SMA (Abcam, 1:200) were used. Sections were incubated in a mixture of the two primary antibodies. Subsequent to overnight incubation at $4^{\circ} \mathrm{C}$, the sections were rinsed three times for $15 \mathrm{~min}$ in $\mathrm{PBS}(0.01 \mathrm{~mol} / \mathrm{l}, \mathrm{pH} 7.4)$ and incubated for $60 \mathrm{~min}$ at $37^{\circ} \mathrm{C}$ in a biotinylation goat anti-mouse $\mathrm{IgG}$ (Invitrogen, 1:8,000). Sections were then incubated for $3 \mathrm{~h}$ at room temperature in a mixture of goat anti-rabbit FITCconjugated IgG (Invitrogen, 1:30) and avidin-conjugated $\mathrm{Cy} 3$ (Sigma, 1:100).

The labeled tissues were then rinsed in PBS $(0.01 \mathrm{~mol} / \mathrm{l}$, $\mathrm{pH}$ 7.4), mounted on gelatin-coated slides and coverslipped. The distribution and intensity of labeling were assessed using a Zeiss epi-illumination fluorescence microscope and a Zeiss LSM 510 confocal laser scanning microscopy system.
The software of the CLSM exhibited images acquired with 495-nm laser illumination (FITC) color-coded in green and those acquired at $543 \mathrm{~nm}(\mathrm{Cy} 3)$ color-coded in red. In each immunostaining run, the two primary antibodies were replaced by non-immune normal goat serum as negative controls.

Pre-embedding immunogold-silver cytochemistry. The expression of Leu-7/ $\alpha$-SMA was explored using pre-embedding immunogold-silver cytochemistry. Sections of $50-\mu \mathrm{m}$ were cut with a vibratome (VT 1000S; Leica, Mannheim, Germany) and placed in PBS containing 25\% sucrose and $10 \%$ glycerol for $1 \mathrm{~h}$ for cryo-protection. Following a freeze-thaw treatment, sections were blocked with 5\% BSA and 5\% NGS for $4 \mathrm{~h}$ to block non-specific immunoreactivity. Subsequent immunohistochemical procedures were performed at room temperature.

For Leu-7/ $\alpha$-SMA double labeling, Leu-7 was detected by immunoperoxidase and $\alpha$-SMA by an immunogold-silver staining method. The sections were incubated overnight in primary antibodies against Leu-7 with those against $\alpha$-SMA, diluted to working concentrations as described above, in PBS containing $1 \%$ BSA and 1\% NGS. Following rinsing in PBS, sections were incubated overnight in a mixture of secondary antibodies of biotinylated goat anti-mouse $\mathrm{IgG}$ and goat anti-rabbit IgG conjugated to 1.4-nm gold particles (1:100, Nanoprobes, Yaphank, NY, USA). In addition, following rinsing in PBS, sections were post-fixed in $2 \%$ glutaraldehyde in PBS for $45 \mathrm{~min}$. Silver enhancement was carried out in the dark with an HQ Silver kit (Nanoprobes). Prior to and following the silver enhancement, sections were rinsed several times with deionized water. The sections were then incubated in ABC solution (Sigma, 1:300) for $4 \mathrm{~h}$ and visualized using the glucose oxidase-3,3'-diaminobenzidine method. Immunolabeled sections were fixed with $0.5 \%$ osmium tetroxide in $0.1 \mathrm{M}$ phosphate buffer for $1 \mathrm{~h}$, dehydrated in graded ethanol series, then in propylene oxide and finally flat-embedded in Epon 812. Following polymerization, the sections were examined under the light microscope. Sections containing Leu-7/ $\alpha$-SMA immunoreactivity were selected, trimmed under a stereomicroscope and mounted onto blank resin stubs. Ultra-thin sections were cut and mounted on mesh grids. The sections were then counterstained with Uranyl Acetate and lead citrate and observed under a JEM-1230 electron microscope (JEOL Ltd., Tokyo, Japan). Electron micrographs were developed in the dark room.

Statistical analysis. Statistical analysis was performed using SPSS 18.0 software (Chicago, IL, USA). To determine the difference of the ability of the levels of PNI and Leu-7 expression between SACC and ACA, statistical analysis was performed using Fisher's exact test. To find the correlation between PNI and Leu-7 expression, $\kappa$ analysis was used. $\mathrm{P}<0.05$ was considered to indicate a statistically significant difference.

\section{Results}

PNI and the expression of Leu-7 in SACC and ACA. PNI appeared in 16 out of 28 SACCs $(57.1 \%)$. In addition, 1 case of PNI was observed microscopically out of the 10 specimens 
Table I. Clinical data and Leu-7 expression in 38 salivary malignancies.

\begin{tabular}{|c|c|c|c|c|c|c|}
\hline Number & Diagnosis & Gender & Age (years) & Tumor site & PNI & Leu-7 \\
\hline 1 & SACC & M & 52 & Left parotid gland & - & + \\
\hline 2 & SACC & M & 57 & Left parotid gland & + & + \\
\hline 3 & SACC & $\mathrm{F}$ & 67 & Right submaxillary gland & + & + \\
\hline 4 & SACC & M & 61 & Right parotid gland & + & + \\
\hline 5 & SACC & $\mathrm{F}$ & 46 & Left submaxillary gland & - & + \\
\hline 6 & SACC & M & 34 & Right parotid gland & + & + \\
\hline 7 & SACC & $\mathrm{F}$ & 55 & Soft palate & + & + \\
\hline 8 & SACC & M & 54 & Right submaxillary gland & - & - \\
\hline 9 & SACC & $\mathrm{F}$ & 52 & Right parotid gland & - & - \\
\hline 10 & SACC & M & 62 & Right palate & + & + \\
\hline 11 & SACC & $\mathrm{F}$ & 66 & Left submaxillary gland & + & + \\
\hline 12 & SACC & M & 31 & Left parotid gland & - & - \\
\hline 13 & SACC & M & 26 & Right palate & - & - \\
\hline 14 & SACC & M & 47 & Right submaxillary gland & - & + \\
\hline 15 & SACC & M & 49 & Left submaxillary gland & + & + \\
\hline 16 & SACC & $\mathrm{F}$ & 41 & Right sublingual gland & + & + \\
\hline 17 & SACC & M & 37 & Left parotid gland & + & + \\
\hline 18 & SACC & $\mathrm{F}$ & 45 & Right parotid gland & + & + \\
\hline 19 & SACC & M & 61 & Left parotid gland & - & + \\
\hline 20 & SACC & $\mathrm{F}$ & 42 & Right submaxillary gland & + & + \\
\hline 21 & SACC & M & 47 & Right submaxillary gland & + & + \\
\hline 22 & SACC & $\mathrm{F}$ & 60 & Right sublingual gland & + & + \\
\hline 23 & SACC & $\mathrm{F}$ & 62 & Right parotid gland & + & + \\
\hline 24 & SACC & M & 67 & Left sublingual gland & - & - \\
\hline 25 & SACC & M & 58 & Right parotid gland & + & + \\
\hline 26 & SACC & $\mathrm{F}$ & 35 & Left sublingual gland & - & - \\
\hline 27 & SACC & M & 39 & Right submaxillary gland & - & + \\
\hline 28 & SACC & $\mathrm{F}$ & 46 & Right parotid gland & - & + \\
\hline 29 & ACA & $\mathrm{M}$ & 59 & Right parotid gland & + & - \\
\hline 30 & ACA & M & 39 & Left sublingual gland & - & - \\
\hline 31 & ACA & $\mathrm{F}$ & 61 & Right palate & - & - \\
\hline 32 & ACA & M & 54 & Left parotid gland & - & - \\
\hline 33 & ACA & $\mathrm{F}$ & 43 & Left parotid gland & - & - \\
\hline 34 & ACA & M & 57 & Right parotid gland & - & - \\
\hline 35 & ACA & M & 65 & Left palate & - & - \\
\hline 36 & ACA & M & 31 & Left sublingual gland & - & - \\
\hline 37 & ACA & $\mathrm{F}$ & 52 & Right sublingual gland & - & - \\
\hline 38 & $\mathrm{ACA}$ & $\mathrm{F}$ & 53 & Right parotid gland & - & - \\
\hline
\end{tabular}

PNI, perineural invasion; SACC, salivary adenoid cystic carcinoma; ACA, acinic cell carcinoma; M, male; F, female.

of ACA (10\%). The H\&E section findings of PNI are summarized in Table I. The differences in the rate of PNI between SACC and ACA were significant (Fisher's exact test, $\mathrm{P}=0.009$; Table II).

Positive staining for Leu-7 was revealed in 22 out of 28 SACCs (78.6\%; Fig. 1a), while none of the 10 ACAs were positive for Leu-7 (Fig. 1b). The differences between SACC and ACA in the expression of Leu-7 were significant (Fisher's exact test, $\mathrm{P}=0.000$; Table II).
Correlation between Leu-7 expression and PNI in SACC. SACCs $(16 / 28)$ were observed with PNI and these were all positive for Leu-7. The $\kappa$ test revealed that there was a significant correlation between Leu-7 expression and PNI $(\kappa=0.533$, $\mathrm{P}=0.01$; Table III).

Double-label immunofluorescence and CLSM for Leu-7/ $\alpha$-SMA. In the SACC, myoepithelial cells were detectable by $\alpha$-SMA staining. In the CLSM images, green fluorescence 
Table II. Differences of ability of PNI and Leu-7 expression between SACC and ACA.

\begin{tabular}{|c|c|c|c|c|c|c|}
\hline & \multicolumn{3}{|c|}{$\mathrm{PNI}^{\mathrm{a}}$} & \multicolumn{3}{|c|}{ Leu-7 expression ${ }^{\mathrm{b}}$} \\
\hline & $(+)$ & $(-)$ & Total & $(+)$ & $(-)$ & Tota \\
\hline SACC & 16 & 12 & 28 & 22 & 6 & 28 \\
\hline $\mathrm{ACA}$ & 1 & 9 & 10 & 0 & 10 & 10 \\
\hline Total & 17 & 21 & 38 & 22 & 16 & 38 \\
\hline
\end{tabular}

PNI, perineural invasion; SACC, salivary adenoid cystic carcinoma; ACA, acinic cell carcinoma. Fisher's exact test: ${ }^{\mathrm{a}} \mathrm{P}=0.009,{ }^{\mathrm{b}} \mathrm{P}=0.000$.
Table III. Correlation between the Leu-7 expression and PNI in SACC.

\begin{tabular}{lrrr}
\hline & \multicolumn{3}{c}{ PNI } \\
\cline { 2 - 4 } & $(+)$ & $(-)$ & Total \\
\hline Leu-7 (+) & 16 & 6 & 22 \\
Leu-7 (-) & 0 & 6 & 6 \\
Total & 16 & 12 & 28 \\
\hline
\end{tabular}

SACC, salivary adenoid cystic carcinoma; PNI, perineural invasion. $\kappa=0.533, \mathrm{P}=0.01$.
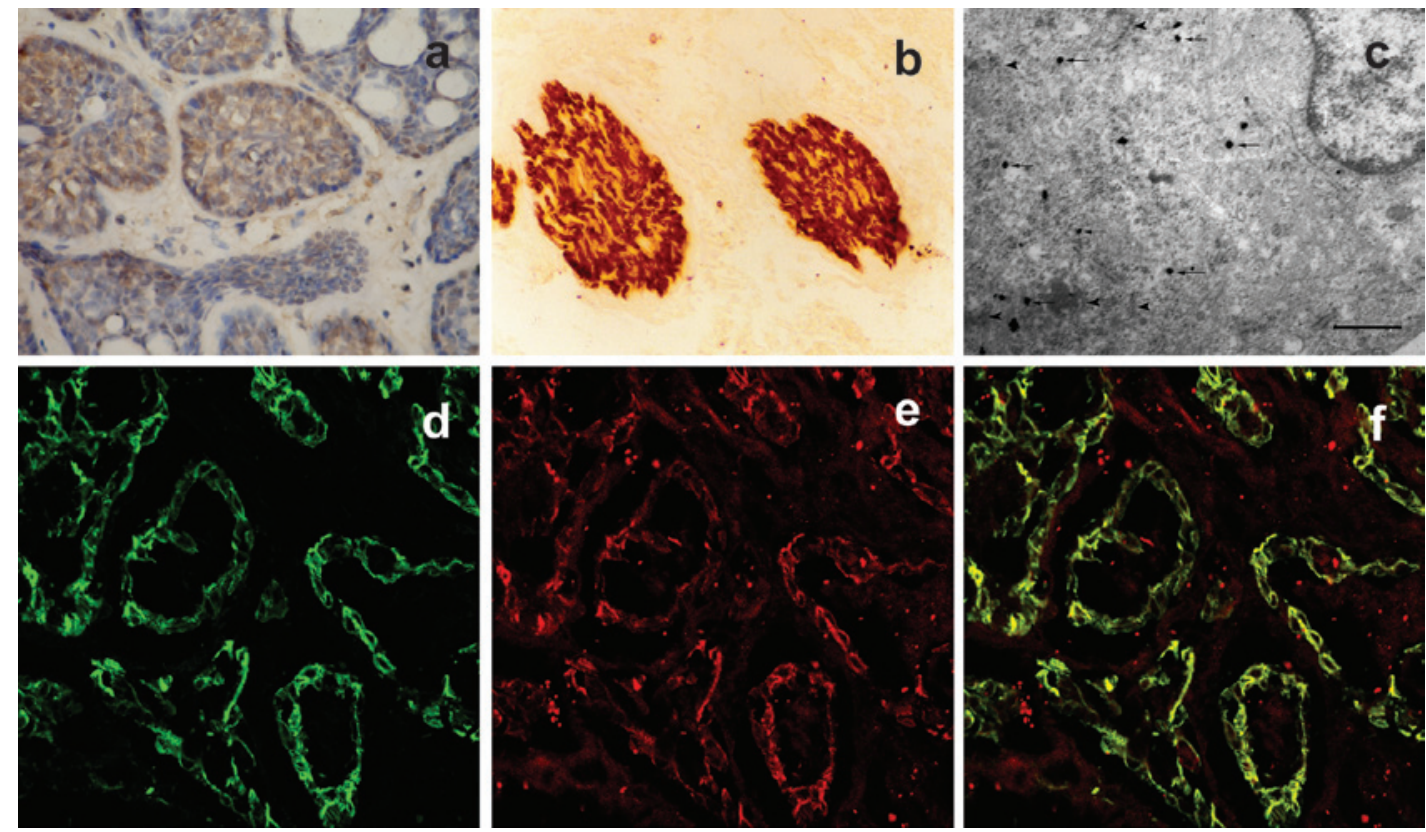

Figure 1. (a) Representative expression of Leu-7 in human SACC which was present diffusely in the cytoplasm of carcinoma cells (original magnification, $\mathrm{x} 400$ ). (b) No Leu-7 expression was detected in human ACA while peripheral nerve tracts revealed strong intensity of staining (original magnification, x200). (c) Electron micrographs showing double labeling of Leu-7 and $\alpha$-SMA in the myoepithelial cell in SACC. Immunogold-silver-enhanced particles, indicative of $\alpha$-SMA immunoreactivity, are revealed diffusely in cytoplasm (arrows). Immunoperoxidase reaction product, indicative of Leu-7 immunoreactivity, is also distributed in cytoplasm (arrowheads). The particles are located in the same myoepithelial cell of the SACC tissue. Scale bars=0.5 $\mu \mathrm{m}$. (d-f) Leu-7/ $\alpha-\mathrm{SMA}$ expressed in human SACC tissues by double-label immunofluorescence (original magnification, x600). (d) Green fluorescence demonstrated positive staining of $\alpha$-SMA. (e) Red fluorescence demonstrated positive staining of Leu-7. (f) Yellow fluorescence demonstrated positive staining of Leu-7/ $\alpha$-SMA, which was co-expressed in the same location. SACC, salivary adenoid cystic carcinoma; ACA, acinic cell carcinoma; $\alpha$-SMA, smooth muscle actin.

revealed positive staining of $\alpha$-SMA, red fluorescence revealed positive staining of Leu-7 and yellow fluorescence revealed green and red fluorescence in the same location (Fig. 1d-f). All 22 SACC cases were double-stained for Leu-7/ $\alpha-S M A$, which were generally localized diffusely in the cytoplasm of myoepithelial cells.

Electron microscopic examination for Leu-7/ $\alpha$-SMA. Under the electron microscope, myoepithelial cells were recognizable by $\alpha$-SMA staining. Immunogold-silver-enhanced particles indicative of $\alpha$-SMA immunoreactivity were present diffusely in the cytoplasm (arrows, Fig. 1c) in SACC. The immunoperoxidase reaction product indicative of Leu-7 immunoreactivity was localized mainly in the cytoplasm (arrowheads, Fig. 1c). Co-expression of Leu-7 and $\alpha$-SMA was identified in the same myoepithelial cells (Fig. 1c).

\section{Discussion}

SACC has a well-documented propensity for PNI. It is recognized as one of the most significant prognostic factors. Previous studies $(13,14)$ have reported the correlation between PNI and poor prognosis. Identification of the potential mechanisms or the influential factors of PNI in SACC is likely to aid in its prevention and treatment. There are several hypotheses for PNI in SACC. In their study, Cheng et al indicated that perineural space invasion was thought to occur by infiltration through the perineural and intraneural lymphatic vessels and/or small veins, or direct invasion of cancer cells along the perineural space, the least resistant tissue (15). Bockman et al suggested that the perineural space provided a suitable microenvironment for the growth of cancer cells (16). Previous studies have shown that Schwann cell markers (p75NTR, 
GFAP) were overexpressed in spindled melanoma in which PNI was observed. Thus, it was speculated that Schwann-like cell differentiation was involved in the process of PNI $(5,6)$.

Leu-7 (HNK-1) belongs to the CD57 antibody group and has been defined as a new Schwann cell marker (7). Overexpression of Leu-7 has been identified in human prostate adenocarcinoma in which PNI was observed (17). The present study has demonstrated that the Schwann cell marker, Leu-7, is expressed in the majority of SACCs. Conversely, all 10 specimens of ACA, which did not have the tendency of PNI, demonstrated negative staining for Leu-7. Furthermore, statistical analysis revealed that the ratio of samples with PNI in positive expression of Leu-7 (72.7\%) was higher than that of negative expression of Leu-7 $(0 \%)$. In addition, the correlation between PNI and Leu-7 expression was shown to be significant through the $\kappa$ analysis $(\kappa=0.533, \mathrm{P}=0.01)$. These results were in accordance with the study of Iwamoto et al on spindled melanoma $(5,6)$. Schwann cells are the principal glial cells of the vertebrate peripheral nervous system. Although these cells serve various functions in the peripheral nerves and ganglia, they are best known for their ability to elaborate the myelin sheath (18). Therefore, we suggest that certain types of cells in SACC differentiate into Schwann-like cells and this is one of the potential mechanisms of PNI in SACC.

SACC tissue contains myoepithelial and canula endothelial cells, while no myoepithelial cells exist in ACA (19). The cells of SACC and ACA were thought to originate from the reserve and multipotent cells of the intercalated duct, respectively (20). Therefore, the tendency of Schwann-like cell differentiation in myoepithelial cells by immunofluorescence staining and electron microscopic examination was investigated. $\alpha$-SMA was used as a myoepithelial marker and Leu-7 as a Schwann cell marker. Therefore, those markers which were double-marked with $\alpha$-SMA and Leu-7 under immunofluorescence staining and CLSM were considered to be transition state cells within the process of differentiation from myoepithelial to Schwann cells. Certain cells were identified with the co-expression of Leu-7/ $\alpha$-SMA in SACC (Fig. 1c-f). The electron microscopic examination also confirmed that Leu-7/ $\alpha$-SMA were co-localized in the cytoplasm of the transition state cells in the SACC sample. These results indicate that Schwann-like cell differentiation occurs in myoepithelial cells of SACC.

Although this study has identified the phenomenon of Schwann-like cell differentiation of myoepithelial cells in SACCs, the exact mechanism and possible influential factors remain to be elucidated. In addition, the morphology and function of the transition state cell require further analysis.

\section{Acknowledgements}

This study was supported by grants from the National Natural Science Foundation of China (nos. 30271424, 30772428 and 81072230) and Natural Science Foundation of Shannxi Province of China (no. 2002C2-06).

\section{References}

1. Yang X, Dai J, Li T, et al: Expression of EMMPRIN in adenoid cystic carcinoma of salivary glands: correlation with tumor progression and patients' prognosis. Oral Oncol 46: 755-760, 2010 .
2. Bhattacharyya N: Survival and prognosis for cancer of the submandibular gland. J Oral Maxillofac Surg 62: 427-430, 2004.

3. van der Wal JE, Snow GB and van der Waal I: Intraoral adenoid cystic carcinoma. The presence of perineural spread in relation to site, size, local extension and metastatic spread in 22 cases. Cancer 66: 2031-2033, 1990.

4. Vrielinck LJ, Ostyn F, van Damme B, van den Bogaert W and Fossion E: The significance of perineural spread in adenoid cystic carcinoma of the major and minor salivary glands. Int J Oral Maxillofac Surg 17: 190-193, 1988.

5. Iwamoto S, Odland PB, Piepkorn M and Bothwell M: Evidence that the p75 neurotrophin receptor mediates perineural spread of desmoplastic melanoma. J Am Acad Dermatol 35: 725-731, 1996.

6. Iwamoto S, Burrows RC, Agoff SN, Piepkorn M, Bothwell M and Schmidt R: The p75 neurotrophin receptor, relative to other Schwann cell and melanoma markers, is abundantly expressed in spindled melanomas. Am J Dermatopathol 23: 288-294, 2001.

7. Nagasaka T, Lai R, Sone M, Nakashima T and Nakashima N: Glandular malignant peripheral nerve sheath tumor: an unusual case showing histologically malignant glands. Arch Pathol Lab Med 124: 1364-1368, 2000

8. Skalli O, Ropraz P, Trzeciak A, Benzonana G, Gillessen D and Gabbiani G: A monoclonal antibody against $\alpha$-smooth muscle actin: a new probe for smooth muscle differentiation. J Cell Biol 103: 2787-2796, 1986.

9. Prasad AR, Savera AT, Gown AM and Zarbo RJ: The myoepithelial immunophenotype in 135 benign and malignant salivary gland tumors other than pleomorphic adenoma. Arch Pathol Lab Med 123: 801-806, 1999.

10. Lazard D, Sastre X, Frid MG, Glukhova MA, Thiery JP and Koteliansky VE: Expression of smooth muscle-specific proteins in myoepithelium and stromal myofibroblasts of normal and malignant human breast tissue. Proc Natl Acad Sci USA 90: 999-1003, 1993.

11. Schön M, Benwood J, O'Connell-Willstaedt T and Rheinwald JG: Human sweat gland myoepithelial cells express a unique set of cytokeratins and reveal the potential for alternative epithelial and mesenchymal differentiation states in culture. J Cell Sci 112: 1925-1936, 1999.

12. Tillie-Leblond I, de Blic J, Jaubert F, Wallaert B, Scheinmann P and Gosset P: Airway remodeling is correlated with obstruction in children with severe asthma. Allergy 63: 533-541, 2008.

13. da Cruz Perez DE, de Abreu Alves F, Nobuko Nishimoto I, de Almeida OP and Kowalski LP: Prognostic factors in head and neck adenoid cystic carcinoma. Oral Oncol 42: 139-146, 2006.

14. Ko YH, Lee MA, Hong YS, et al: Prognostic factors affecting the clinical outcome of adenoid cystic carcinoma of the head and neck. Jpn J Clin Oncol 37: 805-811, 2007.

15. Cheng J, Saku T, Okabe H and Furthmayr H: Basement membranes in adenoid cystic carcinoma. An immunohistochemical study. Cancer 69: 2631-2640, 1992.

16. Bockman DE, Büchler M and Beger HG: Interaction of pancreatic ductal carcinoma with nerves leads to nerve damage. Gastroenterology 107: 219-230, 1994.

17. Genega EM, Hutchinson B, Reuter VE and Gaudin PB: Immunophenotype of high-grade prostatic adenocarcinoma and urothelial carcinoma. Mod Pathol 13: 1186-1191, 2000.

18. Zorick TS and Lemke G: Schwann cell differentiation. Curr Opin Cell Biol 8: 870-876, 1996.

19. Garrett $\mathbf{J}$ and Emmelin $\mathrm{N}$ : Activities of salivary myoepithelial cells: a review. Med Biol 57: 1-28, 1979.

20. Kashani IR, Golipoor Z, Akbari M, Mahmoudi R, Azari S, Shirazi R, Bayat M and Ghasemi S: Schwann-like cell differentiation from rat bone marrow stem cells. Arch Med Sci 7: 45-52, 2011. 